\title{
Peramalan Indeks Harga Saham Gabungan (IHSG) dengan Metode Extreme Learning Machine (ELM)
}

\author{
Afifah Arifia n ty, Mulyono, Med Irzal \\ Jurusan Matematika, Fakultas Matematika dan Ilmu Pengetahuan Alam, \\ Universitas Negeri Jakarta \\ J1. Pemuda 10, Rawamangun, Jakarta Timur 13220, Indonesia \\ afifah_arifianty@yahoo.com \\ December 2, 2015
}

\begin{abstract}
Abstrak Indeks Harga Saham Gabungan (IHSG) merupakan suatu nilai untuk mengukur kinerja seluruh saham. IHSG mencerminkan perkembangan pasar secara keseluruhan. Jika IHSG mengalami kenaikan dari hari kemarin maka dapat disimpulkan beberapa saham yang berada pada bursa efek mengalami kenaikan. Oleh karena itu, peramalan harga akan sangat bermanfaat untuk para investor, sehingga mereka dapat mengetahui prospek investasi saham di masa datang. Ada banyak metode untuk peramalan. Tetapi, metode-metode yang telah ada sebelumnya membutuhkan waktu komputasi yang relatif lebih lama. Metode Jaringan Syaraf Tiruan(JST) dikhawatirkan akan semakin ditinggalkan karena diperlukan waktu yang lama dalam pengambilan keputusan. Untuk mengatasi masalah, Huang (2004) menemukan sebuah metode pembelajaran dalam JST bernama Extreme Learning Machine (ELM). ELM merupakan jaringan syaraf tiruan feedforward dengan satu hidden layer atau lebih dikenal dengan istilah Single hidden Layer Feedforward neural Networks(SLFNs) (Sun et al, 2008). Pada metode ini, faktor yang digunakan dalam peramalan hanya faktor data masa lalu, bukan disebabkan faktor lain seperti politik, ekonomi dan lain-lain.
\end{abstract}

Kata kunci: Indeks Harga Saham Gabungan, Peramalan, Jaringan Syaraf Tiruan, Extreme Learning Machine.

\section{Pendahuluan}

\subsection{Latar Belakang}

Bursa Efek Indonesia (BEI) terus berkembang seiring bertambahnya waktu dan keadaanpun semakin menunjukkan bahwa saham yang merupakan bagian dari BEI semakin banyak peminatnya. Saham merupakan tanda kepemilikan seseorang/badan dalam suatu perusahaan (Darmadji, 2001). Daya tarik investasi saham adalah keuntungan yang diperoleh pemodal dengan membeli saham atau memiliki saham seperti capital gain (keuntun- gan dari hasil jual atau beli saham, berupa selisih nilai jual dan nilai beli saham dimana nilai jual saham lebih besar daripada nilai beli saham), dividen (keuntungan pemegang saham yang diperoleh dari keuntungan perusahaan), dan saham perusahaan, seperti tanah yang nilainya meningkat sejalan dengan waktu.

Namun seiring dengan fluktuasi harga saham, investor dapat mengalami kerugian besar dalam waktu singkat. Oleh karena itu, peramalan harga akan sangat bermanfaat untuk para investor dapat melihat bagaimana prospek investasi saham di masa datang. Dalam menggambarkan pergerakan harga, terdapat indeks harga saham yang berfungsi sebagai indikator trend pasar, indikator tingkat keuntungan, tolok ukur kinerja portofolio, serta penentuan strategi pasif dan produk derivatif. Di Bursa Efek, Indeks Harga Saham 
Gabungan (IHSG) dijadikan indikator awal sebagai patokan harga saham yang merupakan suatu nilai untuk mengukur kinerja seluruh saham.

Untuk memaksimalkan keuntungan dari pasar modal yaitu saham, tidak lagi bergantung pada satu metode saja tetapi ada banyak metode-metode peramalan yang digunakan oleh para investor. Metode-metode tersebut diantaranya adalah dengan Arch, Garch, Jaringan Syaraf Tiruan (JST), dan lain-lain. Pada Jaringan Syaraf Tiruan yang telah diketahui lebih baik dari metode yang lainnya ternyata dapat dikembangkan lagi metodenya untuk peramalan. Tetapi, metode-metode yang telah ada sebelumnya membutuhkan waktu komputasi yang relatif lebih lama sehingga dikhawatirkan metode JST akan semakin ditinggalkan karena diperlukan waktu yang lama dalam pengambilan keputusan. Untuk mengatasi masalah, Huang (2004) menemukan sebuah metode pembelajaran dalam JST bernama Extreme Learning Machine (ELM).

\subsection{Tujuan Penelitian}

Tujuan yang ingin dicapai dalam skripsi ini adalah menganalisis metode Extreme Learning Machine (ELM) dalam memprediksi IHSG dan mendapatkan trend (polapola) yang timbul pada Indeks Harga saham Gabungan (IHSG) dengan melihat data-data saham sebelumnya.

\subsection{Metode Penelitian}

Skripsi ini merupakan studi literatur dalam bidang matematika komputer dan matematika keuangan yang didasarkan pada buku-buku dan jurnal-jurnal tentang teori permasalahan di bidang ekonomi. Referensi utama yang digunakan G.B. Huang, Q.Y. Zhu, dan C.K. Siew (2006).

\section{Landasan Teori}

Landasan teori akan diawali dengan penjelasan tentang Indeks Harga Saham Gabungan (IHSG), peramalan, Jaringan Syaraf Tiruan (JST) kemudian dijelaskan mengenai metode Extreme Learning Machine.

\subsection{Indeks Harga Saham Gabungan (IHSG)}

IHSG menggambarkan suatu rangkaian informal historis mengenai pergerakan harga saham gabungan sampai pada tanggal tertentu. Kenaikan IHSG yang terus menerus menandakan bahwa pasar yang sedang bullish (gejala meningkat) dan indeks harga saham gabungan yang menurun adalah indikator bahwa pasar sedang bearish (gejala beresiko). Rumus untuk menghitung IHSG :

IHSG $=\frac{\sum H_{t}}{\sum H_{0}} * 100 \%$ (Widoatmodjo, 2005)

Keterangan

$\sum H_{t}=$ Total harga semua saham pada waktu yang berlaku

$\sum H_{0}=$ Total harga semua saham pada waktu dasar

\subsection{Peramalan}

Peramalan adalah suatu kegiatan dalam memperkirakan atau kegiatan yang meliputi pembuatan perencanaan di masa yang akan datang dengan menggunakan data masa lalu dan data masa sekarang, sehingga dapat membuat prediksi di masa yang akan datang. 


\subsection{Jaringan Syaraf Tiruan (JST)}

Jaringan syaraf tiruan (JST) merupakan salah satu representasi buatan dari otak manusia yang selalu mencoba mensimulasikan proses pembelajaran pada otak manusia tersebut. Istilah buatan disini digunakan karena jaringan syaraf ini diimplementasikan dengan menggunakan program komputer yang mampu menyelesaikan sejumlah proses perhitungan selama proses pembelajaran.

Jaringan syaraf tiruan memiliki beberapa komponen dasar yang nantinya dapat digunakan untuk mengidentifikasi suatu jaringan syaraf tiruan. Komponen dasar utama dalam jaringan syaraf tiruan adalah neuron. Neuron-neuron yang memiliki fungsi yang sama dikelompokkan dalam suatu lapisan (layer), misalnya neuronneuron yang berfungsi menerima sinyal input dan meneruskannya ke lapisan berikutnya dikelompokkan dalam lapisan input. JST yang memiliki satu atau lebih lapisan yang berada antara input layer dan output (disebut dengan lapisan tersembunyi (hidden layer)) disebut sebagai jaringan syaraf berlapis banyak (multi layer neural network).

Setiap neuron pada jaringan syaraf tiruan menggunakan suatu fungsi aktivasi terhadap input-input yang diterima sebelum diteruskan ke neuron pada lapisan selanjutnya. Fungsi aktivasi $\mathbf{f}(\mathrm{x})$ didefinisikan sebagai fungsi yang menghasilkan suatu nilai yang menunjukkan tingkat keaktifan neuron terhadap input yang masuk. Terdapat tiga tipe dasar fungsi aktivasi yaitu fungsi linear (purelin), fungsi sigmoid biner (logsig), Fungsi Sigmoid Bipolar (tansig).

\section{2,4 Metode Extreme Learning Machine (ELM)}

Metode Extreme Learning Machine (ELM) termasuk metode pembelajaran terawasi karena output yang diharapkan telah diketahui sebelumnya. Metode ini pertama kali diperkenalkan oleh Huang (2004). ELM merupakan jaringan syaraf tiruan feedforward dengan satu hidden layer atau lebih dikenal dengan istilah single hidden layer feedforward neural network(SLFNs) (Sun et al, 2008).

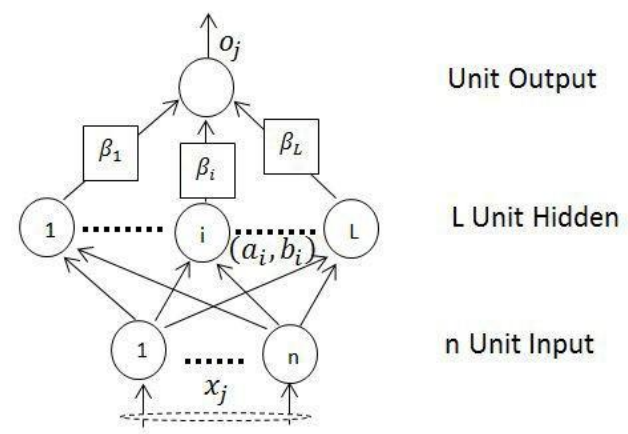

Berdasarkan gambar 1, dapat dibuat model matematika ELM, untuk N sebarang sampel $\left(\mathrm{xi}_{\mathrm{i}}, \mathrm{ti}\right)$ dimana $\mathrm{xi}=\left(\mathrm{xi}_{1}, \mathrm{xi}_{2}, \ldots, \mathrm{xin}\right) \in \mathrm{R}^{\mathrm{n}}$ dan $\mathrm{t}_{\mathrm{i}}=\left(\mathrm{t}_{\mathrm{i}} 1, \mathrm{ti} 2\right.$, . ..., tim) $\in \mathrm{R}^{\mathrm{m}}$, standar SLFNs dengan jumlah unit hidden sebanyak $\mathrm{L}$ dan fungsi aktivasi $\mathrm{g}(\mathrm{x})$ dapat digambarkan secara matematis sebagai berikut :

$$
\sum_{i=1}^{L}
$$

SLFNs dengan $\mathrm{L}$ unit hidden dan fungsi aktivasi $\mathrm{g}(\mathrm{x})$ dapat mendekati $\mathrm{N}$ sampel dengan tingkat error 0 yang berarti $\mathrm{koj}-\mathrm{tj} \mathrm{k}=0$ menjadi oj $=\mathrm{tj}_{\mathrm{j}}$ maka terdapat 
$\beta_{i}$, ai dan bi sedemikian sehingga

Persamaan dapat dituliskan secara sederhana sebagai $\mathrm{H} \beta=\mathrm{T}$ dengan $\mathrm{H}$ adalah matriks yang berisi hasil keluaran dari hidden layer yang berukuran $\mathrm{N} \times \mathrm{L}$, dimana

dengan

Pada ELM bobot input dan bias ditentukan secara acak, maka bobot output yang berhubungan dengan hidden layer dapat ditentukan dari persamaan $\beta=\mathrm{H}^{+} \mathrm{T}$ dengan $\mathrm{H}^{+}$adalah matriks Moore-Penrose Generalized Invers (pseudoinvers) dari matriks $\mathrm{H}$.

Solusi dari persamaan umum sistem linier $\mathrm{Ax}=\mathrm{y}$, dimana $\mathrm{A}$ adalah matriks bukan persegi dapat diperoleh dengan menggunakan Moore-Penrose generalized pseudo invers. Teorema 1 : Misal $\mathrm{G}$ matriks berukuran $\mathrm{n} \times \mathrm{m}$ maka $\mathrm{x}^{*}=\mathrm{Gy}$ adalah solusi minimum norm least squares dari sistem umum linier $\mathrm{Ax}=\mathrm{y}$ jika dan hanya jika $\mathrm{G}=\mathrm{A}^{+}$, Moore-Penrose generalized invers dari A.

\subsection{Peramalan dengan Metode ELM}

Ada beberapa tahap yang harus dilalui pada peramalan dengan metode ELM. Secara garis besar langkah ELM dibagi menjadi empat tahap yaitu pembagian data training dan testing, training ELM, testing ELM dan analisa hasil peramalan. Langkah-langkah peramalan metode ELM secara rinci ditunjukkan pada gambar

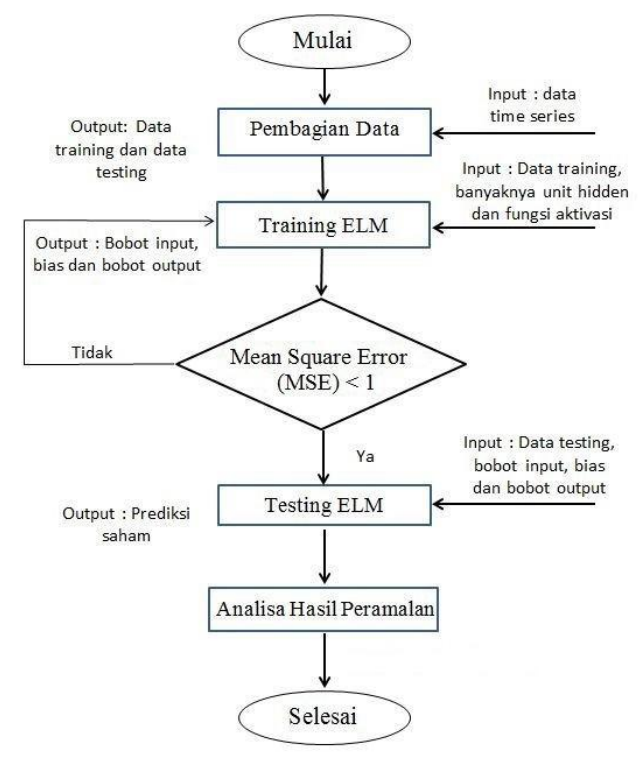

Proses training dan testing mutlak diperlukan pada proses peramalan dengan ELM. Proses training untuk mengembangkan model dari ELM, sedangkan testing digunakan untuk mengevaluasi kemampuan ELM sebagai alat peramalan. Oleh karena itu, data dibagi menjadi dua yaitu data raining dan testing. Menurut Zhang (1997) beberapa peneliti membagi data training dan testing dengan 
komposisi : data training sebanyak $80 \%$ dan data testing $20 \%$ dari total data.

Sebelum digunakan sebagai tool peramalan, ELM harus melalui proses training terlebih dahulu untuk mendapatkan bobot input, bias dan bobot output dengan tingkat kesalahan yang rendah. Langkah-langkah dari proses training ELM sebagai berikut :

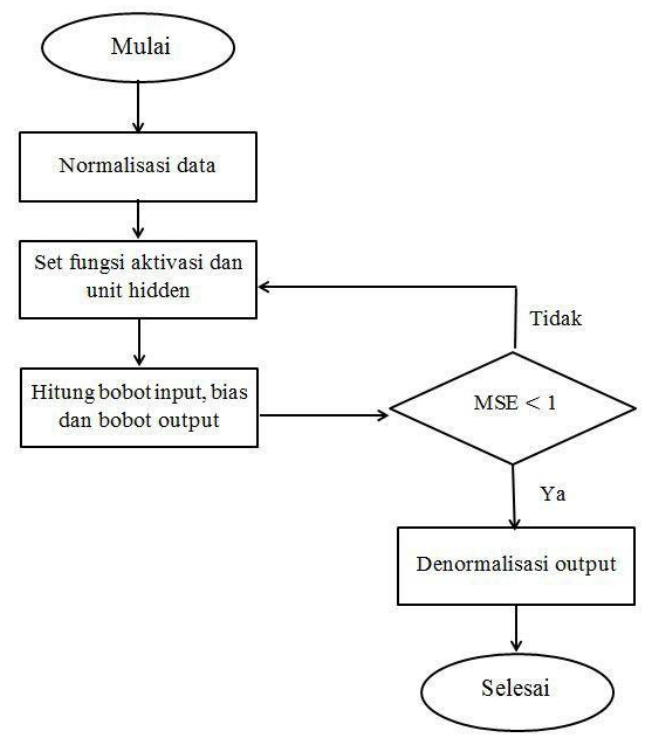

Langkah 1 : Normalisasi Data

Normalisasi perlu dilakukan untuk memastikan bahwa input ELM yang digunakan berada pada interval nilai yang sama, dimana interval tersebut sesuai dengan interval nilai yang digunakan dalam pemodelan ELM. Hal ini sangat berkaitan dengan fungsi aktivasi yang digunakan dan interval nilai yang mungkin terdapat pada variabel tertentu. Fungsi aktivasi yang digunakan akan menghasilkan output dengan interval data $[0,1]$ atau $[-1,1]$. Maka dengan metode pembelajaran ELM, data dinormal- isasikan terlebih dahulu agar data dapat dilatih dengan interval [-1,1] (Huang, 2004). Jika $\mathrm{x}$ adalah input setelah dinormalisasi, xp adalah nilai data asli yang belum dinormalisasi, min ( $\mathrm{xp}$ ) adalah nilai minimum pada data set, dan max (xp) adalah nilai maksimum pada data set, maka transformasi pada persamaan yang digunakan untuk mengubah data menjadi interval $[-1,1]$ adalah :

Langkah 2 : Menentukan Fungsi Aktivasi dan Banyaknya Unit Hidden

Pada proses training banyaknya unit hidden dan fungsi aktivasi dari ELM harus ditentukan terlebih dahulu. Untuk banyaknya unit hidden menurut Sun et al (2008) ELM menghasilkan output peramalan yang stabil dengan banyak unit hidden 0-30. Fungsi aktivasi yang akan digunakan adalah fungsi purelin, log sigmoid, dan tan sigmoid. Namun jika output yang didapat kurang optimal, maka akan digunakan alternatif fungsi aktivasi yang lain atau merubah banyaknya unit hidden.

\section{Langkah 3 : Hitung Keluaran Unit Output}

Output dari proses training ELM adalah bobot input dan output serta bias dari unit hidden dengan tingkat kesalahan rendah yang diukur dengan Mean Square Error (MSE). Bobot input dan bias ditentukan secara random, sedangkan bobot out- put merupakan perkalian pseudoinvers dari matriks unit hidden dengan targetnya. 
$\beta=\mathrm{H}^{+} \mathrm{T}$

Langkah 4 : Denormalisasi Data

Menurut Siang (2005), denormalisasi data pen- ting dilakukan agar data hasil peramalan dengan jaringan syaraf ELM dapat dilihat secara mudah dalam nilai yang sama dengan asalnya. Persamaan menunjukkan rumus yang digunakan untuk denor- malisasi data di dalam interval $[-1,1]$ adalah :

$\mathrm{x}=0,5 *(\mathrm{xp}+1) *(\max (\mathrm{xp})-\min (\mathrm{xp}))+\min (\mathrm{xp}$

dengan $\mathrm{x}$ adalah nilai data setelah denormalisasi, $\mathrm{xp}$ adalah data output sebelum denormalisasi, min (xp) adalah data minimum pada data set sebelum normalisasi, dan $\max (\mathrm{xp})$ adalah data maksimum pada data set sebelum normalisasi.

Berdasarkan bobot input dan output yang dida- pat dari proses training, maka tahap selanjutnya adalah melakukan peramalan dengan ELM (proses testing). Data yang digunakan adalah data testing sebanyak $20 \%$ dari total data. Pada tahap ini data input dinormalisasi terlebih dahulu dengan range dan rumus normalisasi yang sama dengan data training. Secara otomatis output dari proses ini juga harus didenormalisasi.

Setelah melalui berbagai tahapan, maka didapatkan nilai peramalan indeks harga saham gabungan. Hasil yang didapatkan kemudian dianalisa dengan membandingkan tingkat kesalahannya menggunakan MSE. Jika tingkat kesalahan yang dihasilkan masih relatif besar, maka dievaluasi kembali langkah-langkah yang telah dilakukan. Berikut rumus matematis dari Mean Square Error (MSE).

dimana :

$\mathrm{N}=$ jumlah data

oi $=$ data output (prediksi indeks)

$\mathrm{ti}=$ data penutup aktual

\section{Hasil dan Pembahasan}

Dalam penelitian ini data yang digunakan yaitu data indeks harga saham gabungan periode harian dari bulan Januari 2013 sampai dengan bulan Desember 2014. Metode Pengolahan Data yang dilakukan yaitu menggunakan metode Jaringan Syaraf Tiruan dengan menggunakan Matlab. Ada- pun pengolahan datanya adalah mendefinisikan pola masukan dan targetnya. Kemudian dipilih data penutup (close) yang akan digunakan sebagai masukan, pergerakan data penutup dapat dilihat pada gambar 3 .

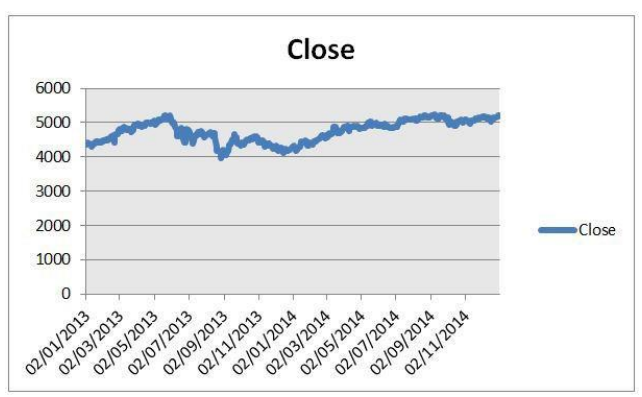


Figure 4: Perubahan IHSG Harian

Data penutup (close) yang dianalisa berjumlah 484 data tetapi setelah dibuat 3 variabel data masukan dan 1 variabel target seperti yang diatas maka data dikurangi 3 yaitu berjumlah 481 data sehingga pembagian data adalah data trainingnya data 1 sampai 385 (385 unit data) dandata testingnya data 386 sampai 481 (96 unit data). fungsi aktivasi yang akan digunakan adalah fungsi purelin, log sigmoid, dan tan sigmoid de- ngan banyaknya unit hidden 3, 5 dan 7. Dengan mengikuti metode peramalan extreme learning machine diperoleh tabel hasil penelitian :

\begin{tabular}{|c|l|c|c|c|}
\hline No. & Fungsi & Hidden & training & testing \\
\hline 1 & Purelin & 3 & 0,0108 & 0,0034 \\
& & 5 & 0,0082 & 0,0033 \\
& & 7 & 0,0082 & 0,0033 \\
2 & \multirow{2}{*}{ Sigmoid } & 3 & 0,0138 & 0,0111 \\
& & 5 & 0,0089 & 0,007 \\
& & 7 & 0,0082 & 0,0033 \\
3 & \multirow{2}{*}{ Tansigmoid } & 3 & 0,0102 & 0,006 \\
& & 5 & 0,0168 & 0,0052 \\
& & 7 & 0,0102 & 0,0056 \\
\hline
\end{tabular}

Dari tabel didapat Mean Square Error (MSE) training paling kecil yaitu pada percobaan 5 dan 7 unit hidden dengan fungsi aktivasi purelin dan 7 unit hidden dengan fungsi aktivasi sigmoid. Berdasarkan proses testing dengan menggunakan model ELM dari proses training diperoleh nilai MSEnya yaitu 0,0033. Dengan demikian, model terbaik yaitu pada percobaan 5 dan 7 unit hidden dengan fungsi aktivasi purelin, serta percobaan 7 unit hidden dengan fungsi aktivasi sigmoid. Dengan trend sebagai berikut:

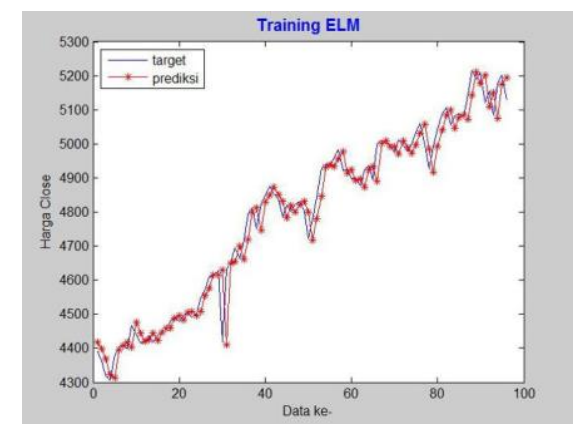

Figure 5: Training 'Purelin' dengan 5 Unit Hidden

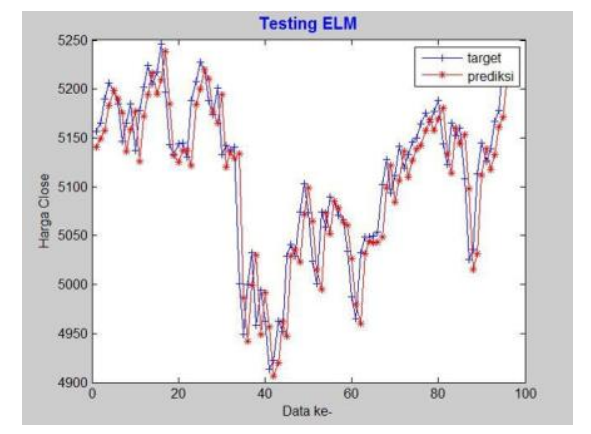


Figure 6: Testing 'Purelin' dengan 5 Unit Hidden 


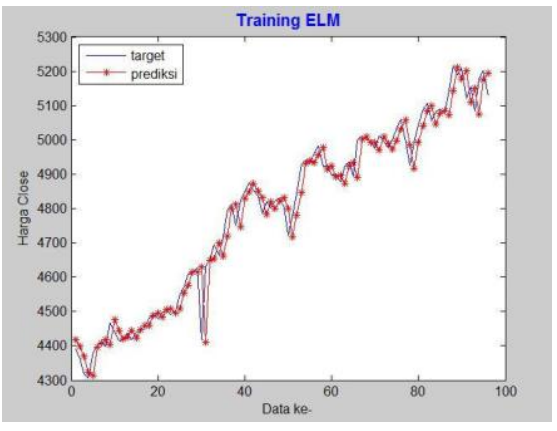

Figure 7: Training 'Purelin' dengan 7 Unit Hidden

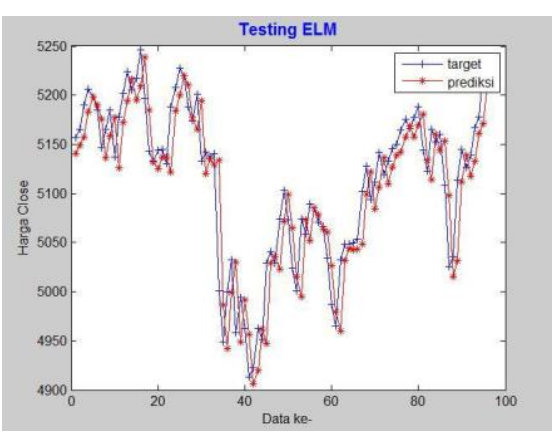

Figure 8: Testing 'Purelin' dengan 7 Unit Hidden

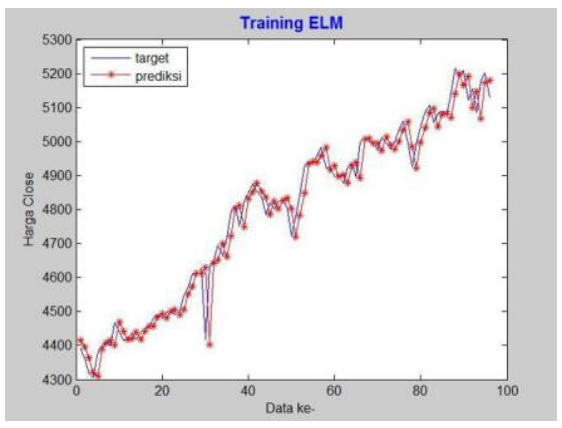

Figure 9: Training 'Sigmoid' dengan 7 Unit Hidden

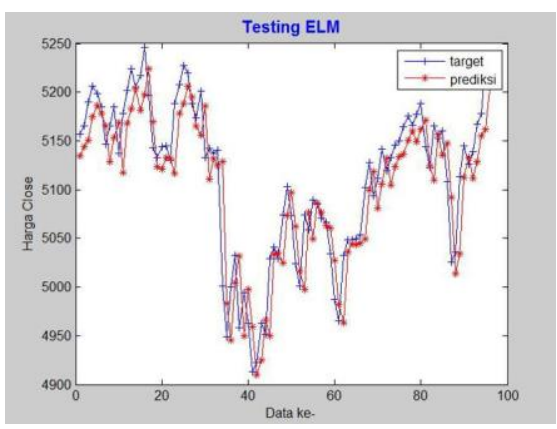

Figure 10: Testing 'Sigmoid' dengan 7 Unit Hidden 


\section{$4 \quad$ Kesimpulan}

Pada peramalan dengan metode extreme learning machine, proses training dan testing mutlak diperlukan. Proses training mengembangkan model dari ELM yaitu bobot input, bias unit hidden, bobot output dan fungsi aktivasinya, sedangkan testing digunakan untuk mengevaluasi kemampuan ELM sebagai alat peramalan.

Berdasarkan proses training, didapatkan output dengan tingkat keakuratan peramalan extreme learning machine, Mean Square Error (MSE) paling kecil yaitu 0,0082 pada program percobaan 5 unit hidden dengan fungsi aktivasi purelin begitupun dengan hasil mse yang sama pada percobaan 7 unit hidden dengan fungsi aktivasi purelin dan 7 unit hidden de- ngan fungsi aktivasi sigmoid.

Berdasarkan proses testing dengan menggunakan model ELM dari proses training diperoleh nilai Mean Square Error (MSE) yaitu 0,0033. Dengan demikian, model terbaik yaitu pada percobaan 5 dan 7 unit hidden dengan fungsi aktivasi purelin, serta percobaan 7 unit hidden dengan fungsi aktivasi sigmoid.

Lamanya waktu yang diperoleh dalam peramalan ELM sangat singkat yaitu rata-rata 0,0269 detik.

\section{Daftar Pustaka}

[1] Agustina, I.D. 2010. "Penerapan Metode Exreme Learning Machine untuk Peramalan Permintaan". Jurusan Sistem Informasi, Institut Teknologi Sepuluh November. Surabaya.

[2] Demuth, H. dan Beale, M. 2014. Neural Network Toolbox For Use with MATLAB. Massachusetts : The MathWork Inc.

[3] Huang, G.B., Zhu, Q.Y., and Siew, C.K. 2006. Extreme Learning Machine:Theory and Applications. Neurocomputing. vol. 70, pp. 489501. http://www.ntu.edu.sg/home/egbhuang

[4] Kusumadewi, S. 2004. "Membangun Jaringan Syaraf Tiruan Menggunakan Matlab \& Excel Link ". Yogyakarta : Graha Ilmu.

[5] Makridakis, S., Wheelwright, S.C., dan McGee,

V.E. 1999. "Metode dan Aplikasi Peramalan". Jakarta : Erlangga.

[6] MacAusland, Ross. 2014. MATH 420: Advanced Topics in Linear Algebra, The Moore-Penrose Inverse and Least Squares. University of Puget Sound. http://buzzard.ups.edu/courses/2014spring/420 projects/math420-UPS-spring-2014macausland-pseudo-inverse.pdf

[7] Siang, J.J. 2005. "Jaringan Syaraf Tiruan dan Pemprogramannya Menggunakan MATLAB”. Yogyakarta : ANDI.

[8] Singh, R. dan Balasundaram, S. 2007. Applica- tion of Extreme Learning Machine Method for Time Series Analysis. World Academy of Sci- ence. 
Engineering and Technology. International Science Index Vol.1 No.11. waset.org/Publication/12152

[9] Timeparticle. 2009. Using the Moore-Penrose Pseudoinverse to Solve Linear Equations. Lin- ear Algebra. https://www.youtube.com/watch?v=5bxsxM2 UTb4

[10] Wickert, Mark. 2015. Statistical Signal Pro- cessing. ECE 5615/4615 Statistical Signal Pro- cessing. 2.3 Linear Algebra : Rectangular Ma- trix. http://www.eas.uccs.edu/wickert/ece5615/

[11] Zhang, G., Pattuwo, B.E., dan Hu, M.Y. 1997. Forecasting with Artificial Neural Network: The State of the Art. Elsevier International Journal of Forecasting 14 (1998) 35-62. 